\title{
COVID-19: A SURVEY ON KNOWLEDGE, AWARENESS AND HYGIENE PRACTICES AMONG DENTAL HEALTH PROFESSIONALS IN AN INDIAN SCENARIO
}

\author{
Ramandeep Singh Gambhirl, Jagjit Singh Dhaliwal ${ }^{2}$,Amit Aggarwal ${ }^{3}$, Samir Anand ${ }^{4}$, \\ Vaibhav Anand ${ }^{5}$, Amanpreet Kaur Bhangu ${ }^{6}$
}
${ }^{1}$ Department of Public Health Dentistry, Rayat and Bahra Dental College and Hospital, Mohali, Punjab, India
${ }^{2}$ PAPRSB Institute of Health Sciences, Universiti Brunei Darussalam, Brunei Darussalam
${ }^{3}$ Department of Oral Medicine and Radiology, MM College of Dental Sciences and Research, MM (Deemed to be University), Mullana, India
${ }^{4}$ Department of General Dentistry, Aesthetics-The Smile Partners, Zirakpur, Punjab, India
${ }_{5}^{5}$ Department of Public Health Dentistry, Shaheed Kartar Singh Sarabha Dental College and Hospital,
Ludhiana, India
${ }^{6}$ Department of General Dentistry, Community Dental Centre, Chandigarh, India

\begin{abstract}
Background. Severe acute respiratory syndrome coronavirus 2 (SARS-CoV-2 or COVID-19) continues to spread globally. It has become a major cause of concern for health care professionals all over the world.

Objective. The aim of this study was to assess knowledge, awareness and hygiene practices regarding COVID-19 among private dental practitioners practicing in Tricity (Chandigarh, Panchkula and Mohali) in India during these critical times. Materials and Methods. A total of 245 private dentists participated in this cross-sectional survey and finally 215 constituted the final sample size. A self-administered, multiple choice type questionnaire (verified by a specialist) was administered to obtain information from the subjects. The questionnaire was divided into two parts and included 15 questions on knowledge and awareness regarding COVID-19. Statistical analysis was done using ANOVA and Student's t-test.

Results. Percentage of subjects who answered correctly regarding main symptoms of COVID-19 and primary mode of transmission was $87 \%$ and $82.5 \%$ respectively. One-third of the subjects were not aware regarding Personal Protective Equipment (PPE) to be used while rendering dental treatment. $75 \%$ of subjects were of the opinion that supportive care is the current treatment regime for COVID-19. Less than one-third of subjects $(30.2 \%)$ reported high scores. Education level $(p=0.018)$ and health sector profile $(p=0.024)$ of the subjects were significantly associated with mean knowledge scores. Conclusion. The findings of the present study showed that some notable deficiencies in knowledge existed among dental professionals regarding some vital aspects of COVID-19. Therefore, there is an urgent need for improving dentists' knowledge via health education and training programs. Further studies on the subject are also warranted once the situation normalizes.
\end{abstract}

Key words: knowledge, pandemics, coronavirus, COVID-19, dentists, emergencies

\section{INTRODUCTION}

COVID-19 (Coronavirus Disease, 2019 \& SARS$\mathrm{CoV}-2)$ is the newly discovered emerging respiratory disease that is caused by a new member of the coronavirus family called novel coronavirus [14]. The epidemic of the disease which started in the month of December 2019 in Wuhan city of China, has become one of the major public health problems of this century and is claiming thousands of lives everyday across the globe [13]. Two main unique features of the virus are its low pathogenicity and high transmissibility that distinguish it from other members of the coronavirus family such as SARS-CoV (Severe Acute Respiratory Syndrome) and MERS-CoV (Middle Eastern Respiratory Syndrome) [12]. It is a highly infectious disease and its clinical symptoms include fever, dry cough, myalgia and fatigue and severe cases progressing to acute respiratory distress syndrome leading to bleeding and coagulation dysfunction [2].

Corresponding author: Dr Ramandeep Singh Gambhir, Department of Public Health Dentistry, Rayat and Bahra Dental College and Hospital, Mohali, Punjab, India, PIN-140104, Tel. +91-99156-46007, Fax-+91-160-5009680, e-mail: raman2g@yahoo.com 
The risk of increased severity is noticed in the elderly and individuals with underlying chronic diseases. Human-to-human transmission of the virus is occurring through airborne droplets, contact or touch of an infected person or from a contaminated surface.

According to recent reports, COVID-19 positive cases have crossed 30000 in India, taking the total number of deaths to 1583 [10]. However, still there is no community transmission of the virus in India as per reports of the Health Ministry barring a few places of virus cluster designated as hot spots. The entire country is in a state of 'Lockdown' (till $3^{\text {rd }}$ May as of now) and the government is issuing advisories on daily basis for its citizens particularly regarding delivery of essential health services and various protective measures to be taken to guard oneself from getting infected; the most important being staying at home (Isolation and Social-Distancing) [10].

Health care workers are amongst the most vulnerable group who have the greatest risk of getting infected. There have been reports of medical staff acquiring the disease while taking care and treating infected individuals [11]. The dental operatory poses a riskier environment because of high possibility of cross-infection between dental practitioners and patients. Although most of the dental clinics are closed during these times, however dental emergencies do come and it's our moral duty to treat them thereby establishing a close contact [6]. A COVID-19 positive case can go symptomless for many days, therefore various guidelines are recommended by Centre for Disease Control and Prevention (CDC) and World Health Organization (WHO) for dental health care workers that adequate precautions can be taken [1, 15]. Still, the exact behaviour of the virus is not fully understood by the scientists, making it even more risky for a health practitioner. Therefore, the present questionnaire survey was carried out to assess the basic essential knowledge, awareness and hygiene practices among dental health professionals regarding COVID-19 in an Indian setting.

\section{MATERIALS AND METHOD}

\section{Ethical clearance and informed consent}

Ethical clearance from the Institutional Ethics Committee and was obtained prior to the start of the study. Informed consent was obtained from the subjects for their willingness to participate in the study. The study was conducted in March, 2020. Participation in the study was voluntary and identification information was not collected from the study subjects.

\section{Study population and study sample}

The present study was a descriptive cross-sectional (questionnaire) study. The study population consisted of dental health professionals who are engaged in private practice in the Tricity (Chandigarh, Panchkula and Mohali). List of all private dental practitioners of the Tricity was obtained from Local Indian Dental Association (IDA) bodies through email.

The sample size required for the study was calculated using the following formula for sample size calculation:

$$
\mathrm{n}=\mathrm{Z}_{1-(\alpha / 2) \times}^{2} \mathrm{~S}^{2} / \mathrm{d}^{2}
$$

where:

$\mathrm{Z}$ - is the standard normal score with $95 \%$ confidence interval (CI) $(\mathrm{a}=0.05)$;

$\mathrm{S}-$ is the standard deviation of the variable;

$\mathrm{d}$ - is maximum acceptable error.

To take account of potential errors and sample loss, which is common in cross-sectional studies, a final sample size was estimated to be 245 .

In order to pick the study subjects from our sampling frame (list of all practicing dentists), a simple random sampling methodology was used. However, only 215 subjects returned the questionnaire that constituted the final study sample.

\section{Research instrument}

A self-designed questionnaire written in English language was made specifically for the study. A specialist in infectious and communicable disease was consulted to verify the content of the questionnaire. The questionnaire was pre-tested for validity and reliability. The reliability of the questionnaire was good (0.84). The questionnaire was divided into two sections: (1) Section A was 'General section' which comprised of socio-demographic and professional details of the subjects (gender, educational status, type of practice etc.). (2) Section $\mathrm{B}$ comprised of 15 questions depicting knowledge and awareness regarding COVID-19 (common symptoms, mode of transmission, availability of vaccine, various preventive measures, details of hygiene practices etc.). The questionnaire was delivered to the study subjects via email and WhatsApp (Social Media Application) and not handed over personally because of city 'Lockdown' to prevent the spread of the virus. The subjects were given one week time to fill the questionnaire and return it. Total knowledge/ awareness score was calculated on the basis of each subject's response. Each positive response was awarded a score of ' 1 ' and negative response as ' 0 '. The total score of the subject was calculated by adding the sum of responses which ranged from 1 to 15 , on a Likert Scale. The final scores were categorized at three levels: low (0-5), medium (6-10) and high (11-15). 


\section{Statistical Analysis}

Calculations were done using descriptive statistical analysis. Number and percentages were used to compute results on categorical measurements. SPSS package version 19.0 (SPSS, Chicago, IL, USA) was used to statistically analyze the results. To find the significance of study parameters between three or more groups of subjects, Analysis of Variance test (ANOVA) was used and Student's t-test was used to find significance between two groups. The significance level was set at $<0.05$.

\section{RESULTS}

Socio-demographic and professional characteristics

Socio-demographic and professional profile of study subjects is depicted in Table 1 . The present study included a total of 215 subjects in which male subjects $(133,61.8 \%)$ were in clear majority as compared to female subjects $(82,38.2 \%)$. Also, more number of subjects held a graduate degree $(120,55.8 \%)$ as compared to subjects holding a post graduate degree in dentistry and majority of the subjects $(127,59 \%)$ were engaged in both academic and private practice. Regarding years of practice, 59 (27.5\%) subjects were practicing for more than 10 years.

\section{Response to questions regarding COVID-19}

Subjects' response towards questionnaire regarding COVID-19is depicted inFigure 1.Percentage of subjects who answered correctly regarding main symptoms of COVID-19 and primary mode of transmission was $87 \%$ and $82.5 \%$ respectively. One-third of subjects $(33 \%)$ were unaware regarding mandatory Personal

Table 1. Socio-demographic and professional profile of study subjects

\begin{tabular}{|c|c|c|c|}
\hline \multirow{2}{*}{ Gender } & Profile & Number & Percentage \\
\hline & Male & 133 & 61.8 \\
\hline \multirow{2}{*}{ Educational status } & Female & 82 & 38.2 \\
\cline { 2 - 4 } & Graduate (BDS) & 120 & 55.8 \\
\hline \multirow{2}{*}{ Health Sector } & Postgraduate (MDS) & 95 & 44.2 \\
\cline { 2 - 4 } & Private clinic & 88 & 41 \\
\hline \multirow{3}{*}{ Years of practice } & Combined (Private \& Academic) & 127 & 59 \\
\cline { 2 - 4 } & Up to 5 & 74 & 34.4 \\
\cline { 2 - 4 } & $5-10$ & 52 & 38.1 \\
\hline
\end{tabular}

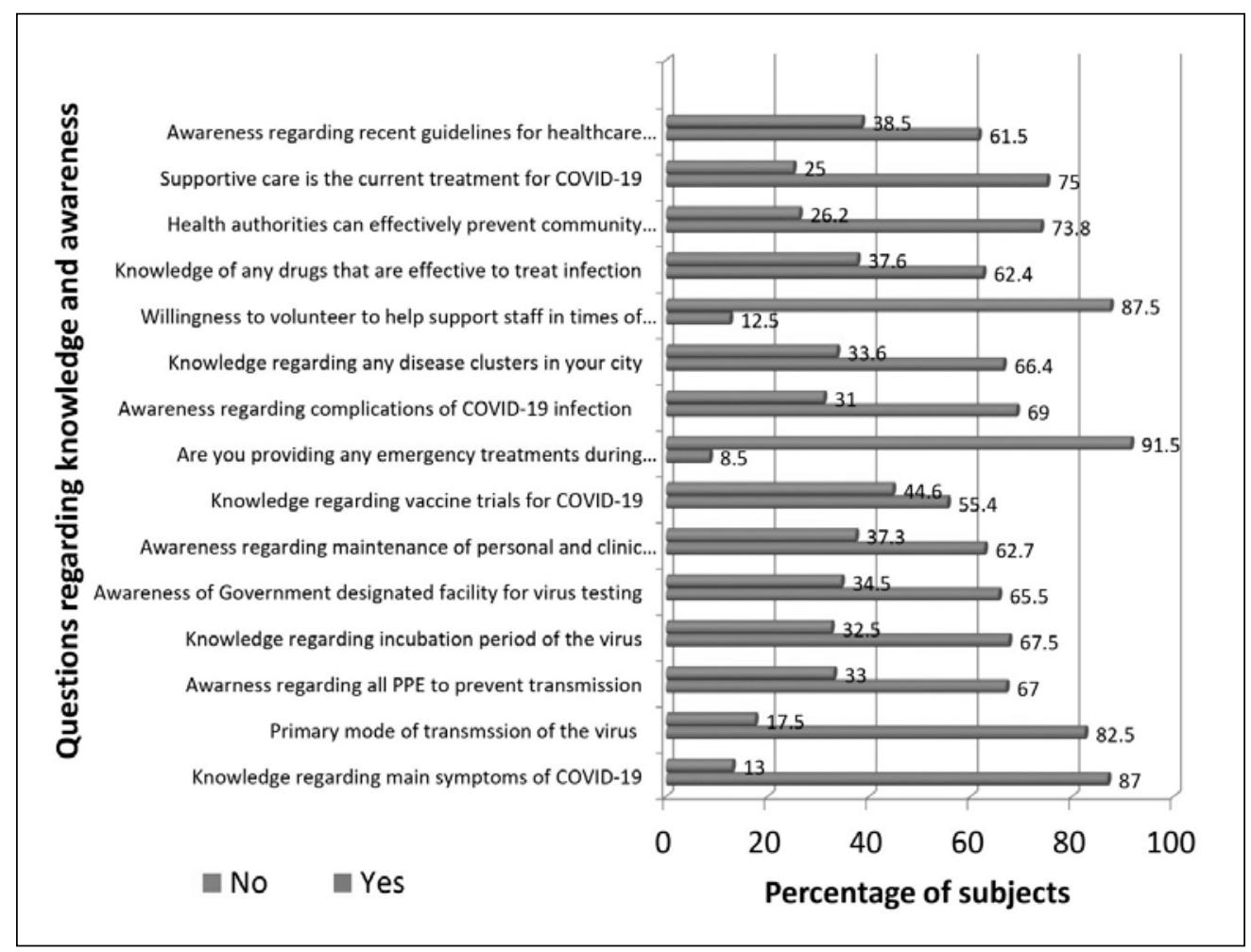

Figure 1. Subjects' response to questionnaire on COVID-19 
Protective Equipment (PPE) that is required while rendering dental treatment. When asked about any nearby government designated facility for virus testing, $64.5 \%$ of subjects answered correctly. Approximately $42 \%$ of subjects had adequate knowledge regarding vaccine trials to prevent COVID-19. Only $8.5 \%$ of the subjects were providing emergency treatment at their practice in these critical circumstances and $12.5 \%$ of subjects showed their willingness to help health workers in times of need. Two-third (75\%) of the subjects were of the opinion that supportive care is the current treatment for COVID-19 and health authorities can effectively prevent community transmission of the virus. In addition, $59.5 \%$ of subjects had knowledge regarding recent guidelines recommended by WHO for health care workers.

\section{Personal and clinic hygiene practices}

Details regarding personal and clinic hygiene practices are mentioned in Figure 2. It was reported that $94.2 \%$ (202) used alcohol rub or soap and water to clean their hands after treating patients. Routinely cleaning and disinfecting clinic surfaces were done by $86.2 \%$ (184) of subjects. Surprisingly, only $35.2 \%$ (75) of subjects were conducting fumigation of the dental operatory every week and only $32.4 \%$ (69) of study subjects were disinfecting the lab work area daily.

\section{Knowledge/awareness level of subjects}

Only $30.2 \%$ (55) of subjects reported high knowledge scores and $38.1 \%$ (92) of subjects were having low knowledge scores (Table 2). There was a statistically significant association of mean knowledge scores with education level $(\mathrm{p}=0.018)$ and health sector profile $(\mathrm{p}=0.024)$ of the subjects whereas no significant difference of knowledge score was observed with gender and years of practice $(p>0.05)$ (Table 3).

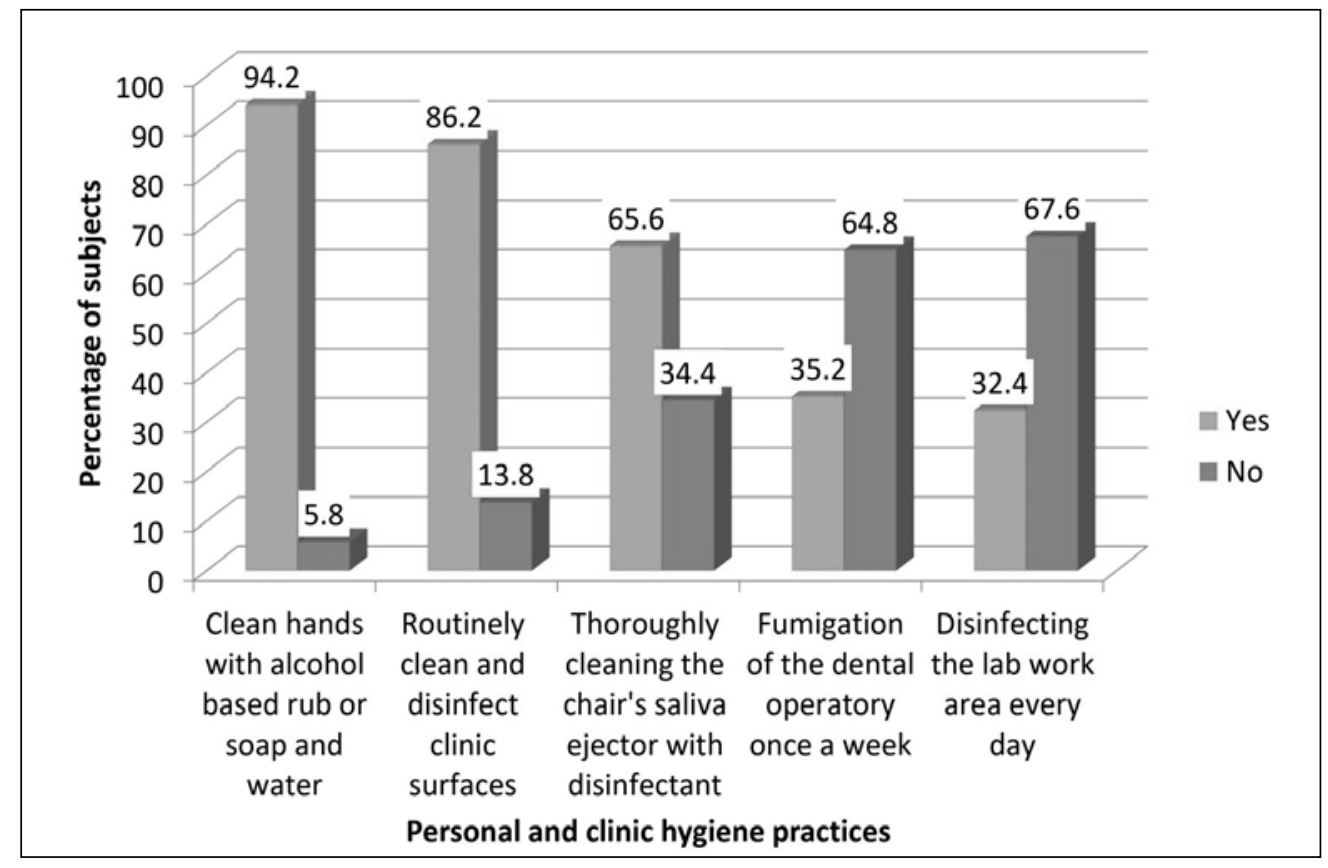

Figure 2. Personal and clinic hygiene practices among subjects

Table 2. Final knowledge scores of study subjects regarding COVID-19 (on the basis of Likert scale)

\begin{tabular}{|c|c|c|c|}
\hline Knowledge score & $\begin{array}{c}\text { Number } \\
\text { of subjects }\end{array}$ & $\begin{array}{c}\text { Percentage } \\
\text { of subjects }\end{array}$ & $95 \%$ CI \\
\hline Low & 82 & 38.1 & $48.27-56.52$ \\
\hline Medium & 68 & 31.6 & $32.42-41.17$ \\
\hline High & 65 & 30.2 & $23.36-29.76$ \\
\hline Total & 215 & 100 & \\
\hline
\end{tabular}


Table 3. Mean knowledge scores of subjects according to different socio-demographic variables

\begin{tabular}{|c|c|c|c|}
\hline Socio-demographic profile & \multicolumn{2}{|c|}{ Knowledge/Awareness score } & P-value \\
\hline Gender & Mean & Standard Deviation & \multirow{4}{*}{$\begin{array}{l}\mathrm{F}=1.512 \\
\mathrm{P}=0.062\end{array}$} \\
\hline Male & 7.42 & 1.36 & \\
\hline Female & 5.36 & 2.62 & \\
\hline Total & 6.39 & 2.65 & \\
\hline \multicolumn{3}{|c|}{ Education level } & \multirow{4}{*}{$\begin{array}{l}\mathrm{F}=2.826 \\
\mathrm{P}=0.018^{*}\end{array}$} \\
\hline Graduate (BDS) & 5.22 & 2.21 & \\
\hline Postgraduate (MDS) & 7.76 & 3.26 & \\
\hline Total & 6.49 & 2.42 & \\
\hline \multicolumn{3}{|c|}{ Health sector } & \multirow{4}{*}{$\begin{array}{l}\mathrm{F}=2.225 \\
\mathrm{P}=0.024^{*}\end{array}$} \\
\hline Private & 5.12 & 1.23 & \\
\hline Combined & 8.01 & 4.55 & \\
\hline Total & 6.56 & 2.54 & \\
\hline \multicolumn{3}{|c|}{ Years of practice } & \multirow{5}{*}{$\begin{array}{l}\mathrm{F}=3.454 \\
\mathrm{P}=0.172\end{array}$} \\
\hline Up to 5 & 4.55 & 3.34 & \\
\hline $5-10$ & 4.67 & 2.75 & \\
\hline More than 10 & 6.71 & 4.21 & \\
\hline Total & 5.31 & 4.12 & \\
\hline
\end{tabular}

$\mathrm{P}<0.05$ (Statistically significant), Tests used: Student $-\mathrm{t}$ test, ANOVA

\section{DISCUSSION}

The pandemic spread by COVID-19 has put the whole world in a state of emergency as thousands of individuals are losing their lives every day because of this life threatening disease [16]. To the best of our knowledge, the present study is first of its kind in the Indian subcontinent examining the knowledge and awareness of dental health professionals regarding this deadly disease. A closeended questionnaire was used in the study in order to achieve a quicker response from the subjects in this state of crisis [4]. It was observed in the study that majority of the subjects had fair knowledge regarding COVID-19 and there were noteworthy deficiencies in some of the important aspects.

Recent research has observed that asymptomatic patients and patients in their incubation period are also carriers of this particular virus which can lead to disease transmission [7]. More than $80 \%$ of subjects were aware of this fact in the present study which is in congruence to findings of some other study as well [6]. The use of PPE, like masks (N-95), gloves, gowns, and goggles or face shields, is recommended to protect skin and mucosa from (potentially) infected blood or respiratory secretions [3]. Appropriate use significantly reduces risk of viral transmission. Astonishingly, onethird of subjects in the present study were not fully aware regarding mandatory PPE which is in contrast to findings of some other studies $[6,11]$.
Following the pandemic alert by WHO, Government of India provided diagnostic facilities for novel coronavirus testing for suspected cases at designated centres throughout the country [10]. More than $60 \%$ of subjects were aware of such facility in our study. The most effective and economical means to prevent and control infectious diseases is though vaccines. While most of the vaccines against COVID-19 are under design and preparation, there are some that have entered efficacy evaluation in animals and initial clinical trials [17]. Only $41.6 \%$ of dental practitioners in our study had basic knowledge regarding vaccine developments.

Dental emergencies can occur and exacerbate in a short period and therefore need immediate treatment. Till now, there has been no consensus on the provision of dental services during the current pandemic [15]. Though it is matter of personal choice, it was observed that $8.5 \%$ of dental practitioners were providing emergency dental services at their clinic. Moreover, $12.5 \%$ of the subjects were willing to help health care workers in case there is shortage of health care staff.

Currently there is no specific treatment available to treat COVID-19, so the management of COVID-19 has been largely supportive that includes infection prevention and control measures to lower the risk of transmission and isolation [9]. Two-third of the subjects in our study agreed to this fact which is in contrast to findings of a recent study conducted on health care workers in China [5]. The present study also reported 
that more than $60 \%$ of subjects were knowledgeable regarding recent WHO guidelines for health care workers while dealing with COVID-19 patients.

Hand hygiene has been considered the most vital measure for minimizing the risk of transmitting microorganism to patients [8]. More than $90 \%$ of subjects used alcohol rub or soap and water to clean their hands after treating patients in our study. Coronavirus- 2 can persist on surfaces for a few hours or up to several days, depending on the nature of surface, the temperature, or the humidity of the environment [15]. A vast majority of subjects were routinely cleaning and disinfecting clinic surfaces in the study. Fumigation of the dental operatory with drawers open should be done at least once a week to make the operating area completely sterile. However, hardly one-third of subjects fumigated their clinics in this study.

Subjects holding a post-graduate degree were more knowledgeable as compared to graduates, stressing the positive impact of education on knowledge scores $(\mathrm{p}=0.018)$. Moreover, knowledge scores of subjects doing combined practice were more as compared to subjects doing only private practice $(\mathrm{p}=0.024)$. This could be due to the reason that subjects engaged in academic teaching are exposed to more learning experiences which can lead to regular knowledge updating. However, there was no statistically significant relationship between knowledge scores and years of practice (work experience) of subjects $(p>0.05)$ which is in agreement with findings of another study on health care workers [5].

The present study had few limitations as well. The sample size utilized in the study is small because the whole city is under 'Lockdown' as panic created by the pandemic has kept the people homebound who are busy managing their personal affairs. As a result, certain aspects related to COVID-19 could have been possibly left behind. Moreover, the study relied upon self-reported data, which is dependent upon subjects' honestly and recall ability. Thus it may give rise to recall bias.

\section{CONCLUSION}

The present study concluded that most of the subjects had fair knowledge regarding COVID-19, yet there were significant knowledge gaps in some of the important aspects like knowledge regarding PEE, vaccine trials etc. as less than one-third of subjects reported high scores. These findings clearly indicate the importance of improving subjects' COVID-19 knowledge via health education and training programs on infection control and hygiene practices for COVID-19 across all healthcare professions. With better understanding of viral features, epidemiologic characteristics, clinical spectrum, and treatment, efficient strategies can be formed to prevent, control, and stop the spread of COVID-19. Recent guidelines recommended by WHO and CDC should be followed while treating patients in dental practices and dental schools. Further studies involving larger sample size should be conducted once things are under control and this deadly disease is eradicated from the world. Lastly, as a health care professional, it's our moral duty to support health care workforce in times of need during this global epidemic.

\section{REFERENCES}

1. Centers for Disease Control and Prevention (CDC). CDC Developing Guidance Regarding Responding to COVID-19 in Dental Settings. Division of Oral Health, National Center for Chronic Disease Prevention and Health Promotion. Available from: https://www.cdc. gov/oralhealth/infectioncontrol/statement-COVID. html. Accessed on 11th April 2020.

2. Chen N., Zhou M., Dong X., Qu J., Gong F., Han Y., Qiu Y., Wang J., Liu Y., Wei Y., Xia J., Yu T., Zhang X., Zhang.: Epidemiological and clinical characteristics of 99 cases of 2019 novel coronavirus pneumonia in Wuhan, China: a descriptive study. Lancet. 2020;395:507-13.

3. Cook T.M.: Personal protective equipment during the COVID-19 pandemic - a narrative review. Anaesthesia. 2020. doi: 10.1111/anae.15071.

4. Desai S.C., Reimers S.: Comparing the use of open and closed questions for Web-based measures of the continued-influence effect. Behav Res. 2019; 51:1426-40.

5. Huynh G., Nguyen T.N.H., Tran V.K., Vo K.N., Vo V.T., Pham L.A.: Knowledge and attitude toward COVID-19 among healthcare workers at District 2 Hospital, Ho Chi Minh City. Asian Pac J Trop Med. 2020;13. doi: 10.4103/1995-7645.280396.

6. Khader Y.S., Nsour M.A., Al-Batayneh O.B., Saadeh R., Basheir H., Alfaqih M., Al-Azzam S., AlShurman B.A.: Dentists' awareness, perception, and attitude regarding COVID-19 and infection control: A cross-sectional study among Jordanian dentists. JMIR Public Health Surveill. 2020;6:e18798.

7. Kolifarhood G., Aghaali M., MozafarSaadati H., Taherpour N., Rahimi S., Izadi N., Hashemi Nazari S.S.: Epidemiological and Clinical Aspects of COVID-19; a Narrative Review. Arch AcadEmerg Med. 2020;8:e41.

8. Larson E.L., Early E., Cloonan P., Sugrue S., Parides M.: An organizational climate intervention associated with increased handwashing and decreased nosocomial infections. Behav Med. 2000:26(1):14-22.

9. Meng L., Hua F., Bian Z.:Coronavirus Disease 2019 (COVID-19): Emerging and Future Challenges for Dental and Oral Medicine. J Dent Res. 2020. doi: $10.1177 / 0022034520914246$.

10. Ministry of Health and Family Welfare, Government of India [homepage on the internet]. Available at: www. mohfw.gov.in Accesses on $5^{\text {th }}$ May 2020.

11. Modi P.D., Nair G., Uppe A., Modi J., Tuppekar B., Gharpure A.S, Langade G.: Awareness Among 
Healthcare Students and Professionals in Mumbai Metropolitan Region: A Questionnaire-Based Survey. Cureus. 2020;12: e7514. DOI 10.7759/cureus.7514.

12.Nemati M., Ebrahimi B., Nemati F.: Assessment of Iranian Nurses' Knowledge and Anxiety Toward COVID-19 During the Current Outbreak in Iran. Arch Clin Infect Dis 2020. In Press (In Press):e102848.

13. Phelan A.L., Katz R., Gostin L.O.: The novel coronavirus originating in Wuhan, China: challenges for global health governance [epub ahead of print 30 Jan 2020] in press. JAMA. doi:10.1001/jama.2020.1097.

14. The Novel Coronavirus Pneumonia Emergency Response Epidemiology Team. The epidemiological characteristics of an outbreak of 2019 novel coronavirus diseases (COVID-19) in China. Chin J Epidemiol. 2020; 41:145-51.
15. The World Health Organization (WHO). Clinical management of severe acute respiratory infection when novel coronavirus ( $\mathrm{nCoV}$ ) infection is suspected: Interim guidance. Available from: https://www.who. int/emergencies/diseases/novel-coronavirus-2019. Accessed on $11^{\text {th }}$ April 2020.

16. Velavan T.P., Meyer C.G.: The COVID-19 epidemic. Trop Med Int Health. 2020;25:278-80.

17. Zhang J., Zeng H., Gu J., Li H., Zheng L., Zou Q.: Progress and Prospects on Vaccine Development against SARS-CoV-2. Vaccines (Basel). 2020;8. pii: E153. doi: 10.3390/vaccines 8020153 .

Received: 17.04 .2020

Accepted: 06.05.2020 